\title{
Combined hyperactive dysfunction syndrome of the cranial nerves
}

INSERM

\section{Source}

INSERM. (1999). Orphanet: an online rare disease and orphan drug data base. Combined hyperactive dysfunction syndrome of the cranial nerves. ORPHA:221078

Combined hyperactive dysfunction syndrome of the cranial nerves is a rare, acquired peripheral neuropathy characterized by symptoms arising from combined overactivity in cranial nerves, without any explanatory structural lesion. The symptoms may be unilateral or bilateral, may occur synchronously or metachronously, and include trigeminal neuralgia, hemifacial spasm and glossopharyngeal neuralgia. 